Research Paper

\title{
Switching Lamivudine with Adefovir Dipivoxil Combination Therapy to Entecavir Monotherapy Provides Better Viral Suppression and Kidney Safety
}

Jiang-Shan Lian' ${ }^{1}$, Xiao-Lin Zhang1,3, Ying-Feng Lu' ${ }^{1}$, Jian-Yang Chen ${ }^{1}$, Yi-Min Zhang ${ }^{1}$, Hong-Yu Jia ${ }^{1}$, Zhe Zhang ${ }^{2}$, Yi-Da Yang, ${ }^{1,}$

1. Collaborative Innovation Center for Diagnosis and Treatment of Infectious Diseases, State Key Laboratory for Diagnosis and Treatment of Infectious Diseases, Department of Infectious Diseases, The First Affiliated Hospital, School of Medicine, Zhejiang University. Hangzhou 310003, China

2. Urology Department, The First Affiliated Hospital of Zhejiang University, School of Medicine, Zhejiang University. Hangzhou 310003, China

3. Shanghai Public Health Clinical Center, Shanghai Public Health Clinical Center Affiliated to Fudan University

$\triangle$ Corresponding author: Yi-Da Yang, Collaborative Innovation Center for Diagnosis and Treatment of Infectious Diseases, State Key Laboratory for Diagnosis and Treatment of Infectious Diseases, Department of Infectious Diseases, The First Affiliated Hospital, School of Medicine, Zhejiang University, Hangzhou 310003, China; Email: yidayang65@zju.edu.cn, Tel: +86-13857121518

(C) Ivyspring International Publisher. This is an open access article distributed under the terms of the Creative Commons Attribution (CC BY-NC) license (https://creativecommons.org/licenses/by-nc/4.0/). See http://ivyspring.com/terms for full terms and conditions.

Received: 2018.07.23; Accepted: 2018.10.18; Published: 2019.01.01

\begin{abstract}
Introduction: Most chronic hepatitis $B(C H B)$ patients in China are primitively treated with a combination of lamivudine (LAM) and adefovir dipivoxil (ADV). Although antiviral resistance can be avoided with this combination therapy, using it can have harmful side effects related to ADV, specifically kidney and bone injury. This study was designed to compare viral suppression and kidney safety when switching LAM and ADV combination therapy de novo to entecavir (ETV) monotherapy in patients with $\mathrm{CHB}$ and compensated hepatic cirrhosis.
\end{abstract}

Materials and methods: In total, $360 \mathrm{CHB}$ and compensated liver cirrhosis patients who received treatment of LAM and ADV combination therapy for more than 1 year were included in this study. One hundred and eighty patients continued combination therapy to serve as a control group and the other 180 patients were switched to ETV monotherapy to serve as the experimental group. The total course of therapy was 3 years. Laboratory studies were done every 3 months to measure liver and kidney function. Studies included glomerular filtration rate (eGFR), HBV-DNA, urine $\beta 2$-microglobulin ( $\beta 2-M)$ and retinol binding protein (RBP).

Results: In the experimental group, an HBV-DNA level below $20 \mathrm{IU} / \mathrm{ml}$ was found in $77.65 \%$, $85.88 \%$, and $94.77 \%$ in years 1,2 , and 3 , respectively. In the control group, HBV-DNA levels were below $20 \mathrm{IU} / \mathrm{ml}$ in $69.66 \%, 75.42 \%$, and $85.80 \%$ in years 1, 2, and 3, respectively. Low HBV-DNA levels in the experimental group were significantly less common than in the control group on the second and third year; $P$ values were 0.009 and 0.006 for years 2 and 3 , respectively. The cumulative genetic mutation rate was $3.49 \%$ in the experimental group and $8.88 \%$ in the control group $(P=0.044)$. Decreases in eGFR more than $30 \%$ from baseline were found in $0 \%, 0.56 \%$, and $1.74 \%$ of patients in the experimental group and $4.49 \%, 9.14 \%$ and $14.79 \%$ in patients in the control group in the first, second, and third year, respectively. Serum creatinine more than $50 \mu \mathrm{mol} / \mathrm{L}$ above baseline was found in $0 \%, 0 \%$ and $1.74 \%$ of patients in the experimental group and $1.12 \%, 4.00 \%$ and $5.32 \%$ of patients in the control group in years 1,2 , and 3 , respectively. The urine $\beta 2-M$ and RBP levels were abnormal more often in the experimental group than in the control group.

Conclusion: Switching to ETV monotherapy can decrease HBV-DNA levels, reduce the genetic mutation rate, and prevent renal damage caused by LAM and ADV combination therapy in patients with $\mathrm{CHB}$ and compensated liver cirrhosis. Patients receiving LAM and ADV combination therapy de novo should be switched to ETV monotherapy immediately.

Key words: ETV, LAM and ADV combination therapy de novo; switch; kidney safety 


\section{Introduction}

Lamivudine (LAM) was the first approved oral drug to treat hepatitis B virus (HBV) infection. Its introduction brought about a new era in the treatment of chronic hepatitis B (CHB); however, the use of LAM is limited because it is associated with a high rate of antiviral resistance.[1] Combination therapy with adefovir dipivoxil (ADV), as well as other methods, has been widely accepted to decrease the occurrence resistance and relapse after achieving complete remission.[2, 3] Although combination therapy with ADV can prevent the development of resistance, it does not prevent the side effects of ADV, specifically injury to the kidney and bone.[4] Because of the risk of developing resistance, LAM and LAM combined with ADV are not recommended as the first-line drug for HBV infection. The first-line agents currently recommended are entecavir (ETV) and tenofovir disoproxil fumarate (TDF), for which emergence of resistance is very low. [5, 6] TDF may also increase the risk of kidney damage.[7-9] ETV demonstrated superior virologic efficacy and greater improvement of liver histology compared to ADV monotherapy or LAM monotherapy in patients with chronic hepatitis B.[10] Is it safe and efficacious to switch LAM and ADV combination therapy de novo to ETV monotherapy in patients with $\mathrm{CHB}$ and compensated liver cirrhosis? There is still no effective clinical evidence on this topic. This study was designed to analyze the efficacy and safety of switching LAM and ADV combination therapy de novo to ETV monotherapy in patients with $\mathrm{CHB}$ and Compensated Hepatic Cirrhosis.

\section{Materials and Methods}

\section{Objects of study}

In this study, 273 patients with $\mathrm{CHB}$ and 87 patients with $\mathrm{HBV}$ infection and compensated hepatic cirrhosis from the First Affiliated Hospital of Zhejiang Medical University (Hangzhou, China) between June 2011 to June 2013 were enrolled. Pathology was confirmed based on medical history, physical examination, laboratory findings, ultrasound and radiological signs of cirrhosis. Patients with $\mathrm{CHB}$ and compensated hepatic cirrhosis were diagnosed according to the guideline of prevention and treatment for chronic hepatitis B (2010 version) proposed by the Chinese Medical Association Chinese Society of Hepatology and Chinese Society of Infectious Diseases.[11] All patients were adults ages 18 to 65 years and received de novo therapy of LAM and ADV for more than 1 year. Patients coinfected by hepatitis C-like virus, hepatitis delta virus or human immunodeficiency virus (HIV) were not included.
Patients with HCC, alcoholic liver cirrhosis, autoimmune hepatitis, decompensated liver cirrhosis, hepatorenal syndrome, hepatic encephalopathy, spontaneous bacterial peritonitis, or other diseases such as cardiopathy, nephrosis, and cerebropathy were not included. Patients with an estimated glomerular filtration rate $(e G F R) \leq 60 \mathrm{ml} / \mathrm{min} / 1.73$ $\mathrm{m} 2$ were also excluded from this study. Informed consent was obtained from all patients and they understood all aspects of the experiment. The agreement was received by the Ethics Committee of the First Affiliated Hospital of Zhejiang University.

\section{Project design}

The project was carried out as a prospective case-control study. Of the 360 patients enrolled, 180 patients continued LAM and ADV combination therapy as the control group. The other 180 patients were switched to ETV monotherapy as the experimental group. Patients were randomly assigned to a group. Baseline data from both groups were compared to confirm comparability. The experimental group patients received $0.5 \mathrm{mg}$ of ETV daily, and the control group patients received $100 \mathrm{mg}$ of LAM and $10 \mathrm{mg}$ of ADV daily.

\section{Follow-up studies}

The experiment used commercially available enzyme immunoassays (Abbott Laboratories, Chicago, IL, United States) to detect serum hepatitis B viral markers. Serum HBV-DNA was tested using polymerase chain reaction (PCR) with a linear range between 20 and $1.8 \times 108 \mathrm{IU} / \mathrm{mL}$ (Roche Light Cycler 480 Real-time PCR System, Switzerland). Measurements from both groups were taken at the beginning of weeks 0, 24, 48, 72, 96, 120 and 144 . Follow-up clinical assessments including physical examination, serum hepatitis B viral markers, HBV-DNA quantitative check, serum biochemistry, a-fetoprotein, kidney function, blood coagulation time, and ultrasonography were also performed. The eGFR (detected as $\mathrm{mL} / \mathrm{min} / 1.73 \mathrm{~m} 2$ ) was calculated using the Chinese formula [175 $\times$ Pcr1.234 $\times$ age 0.179 (female $\times 0.79)$ ]. Kidney injury was defined as a decrease in eGFR to below $50 \mathrm{~mL} / \mathrm{min} / 1.73 \mathrm{~m} 2$. Urine $\beta 2-\mathrm{M}$ and RBP of urine were also measured; $0.000-0.025 \mathrm{~g} / \mathrm{mol}$ creatinine was considered normal. Patient status after 144 weeks is shown in Figure 1.

\section{Statistical analysis}

Continuous variables were presented as the means $\pm \mathrm{SD}$ and compared between the groups using Student's $t$ test. Serum HBV DNA levels were compared after conversion to a logarithmic scale. Proportions were presented as percentages (\%), and 
rate comparisons were performed using the $\chi^{2}$ test. The cumulative incidence of urine $\beta 2-\mathrm{M}$ and RBP abnormalities were calculated using the Kaplan-Meier method, and group data were calculated using the log rank test. Statistical analyses were performed using SPSS version 16.0 (SPSS, Chicago, IL, USA). P values less than 0.05 were considered significant.

\section{Results}

\section{Baseline characteristics}

Over the course of the study, of the 180 patients in the control group, 11 were lost to follow-up and 15 underwent genetic mutation. Of the 180 patients in the experimental group, 8 were lost to follow-up and 6 underwent genetic mutation. During follow-up, 1 patient was found to have developed liver cancer in year 2, and another patient was found to have developed liver cancer in year 3 in the control group. In the experimental group, 1 patient developed liver cancer in year 3. No patients developed complications such as ascites, hepatic encephalopathy, and upper gastrointestinal bleeding in either group. Baseline characteristics of patients from the study and control groups were presented in Table 1. No significant differences were found between both groups.

\section{Virological response and genetic mutation}

The baseline level of HBV-DNA was $2.11 \pm 0.49$ $\log \mathrm{IU} / \mathrm{ml}$ in the control group and $2.14 \pm 0.45 \mathrm{log}$ $\mathrm{IU} / \mathrm{ml}$ in the experimental group. During follow-up, the percentage of patients with HBV-DNA levels below $20 \mathrm{IU} / \mathrm{ml}$ were $69.66 \%$ (124/178), $75.42 \%$ $(132 / 175)$ and $85.8 \%(145 / 169)$ in the control group and $77.65 \%(139 / 179), 85.88 \%(152 / 177)$ and $94.77 \%$ $(163 / 172)$ in the experimental group in years 1,2 and
3 , respectively. The occurrence of virological response in the experimental group was higher than in the control group. Of the 180 patients in the control group, $1.69 \%(3 / 178), 4.00 \%(7 / 175)$ and $8.88 \%$ $(15 / 169)$ had genetic mutations in years 1, 2 and 3, respectively. Eight patients had the rtM $204 \mathrm{~V}$ mutation, five patients had the rtM204I mutation, one patient had the rtN236T mutation and one patient had the rtA181V+N236T mutation. By comparison, $0 \%$ $(0 / 179), 1.68 \%(3 / 177)$ and $3.49 \%(6 / 172)$ of the 180 patients in the experimental group had genetic mutations in years 1,2 , and 3 , respectively. Three patients had the rtM204V, rtL180M and rtS202G mutations and two patients had the rtM204V, rtL180M and rtT184A mutations. The results of the two groups were significantly different by the third year $(\mathrm{P}=0.044)$, as shown in Table 2 .

Table 1. Baseline characteristics of patients with chronic hepatitis $\mathrm{B}$ and $\mathrm{HBV}$-related compensated cirrhosis

\begin{tabular}{llll}
\hline Variables & LAM+ADV (n=180) & ETV(n=180) & P value \\
\hline Age (yr) & $43.5 \pm 10.3$ & $44.6 \pm 9.8$ & 0.789 \\
Male/female & $142 / 38$ & $148 / 32$ & 0.424 \\
Treatment duration (mo) & $16.8 \pm 7.9$ & $17.6 \pm 8.4$ & 0.445 \\
Body weight (kg) & $67.5 \pm 13.8$ & $68.9 \pm 16.7$ & 0.289 \\
Liver cirrhosis (\%) & $21.1 \%$ & $21.7 \%$ & 0.898 \\
HBeAg(+) (\%) & $61.1 \%$ & $62.2 \%$ & 0.828 \\
HBV DNA(log IU/ml) & $2.13 \pm 0.5$ & $2.15 \pm 0.4$ & 0.352 \\
ALT (U/L) & $46.7 \pm 11.3$ & $48.7 \pm 12.4$ & 0.876 \\
TBil $(\mu$ mol/L) & $27.7 \pm 8.9$ & $25.8 \pm 10.1$ & 0.787 \\
Alb $(\mathrm{g} / \mathrm{L})$ & $43.8 \pm 7.6$ & $44.3 \pm 8.5$ & 0.687 \\
Cr $(\mu \mathrm{mol} / \mathrm{L})$ & $57.8 \pm 6.7$ & $58.7 \pm 8.9$ & 0.638 \\
eGFR (ml/min/1.73/m²) & $93.6 \pm 15.8$ & $92.1 \pm 12.7$ & 0.657 \\
$\left.\beta 2-\mathrm{M}(\mathrm{g} / \mathrm{mol} . \mathrm{Cr}) \times 10^{-2}\right)$ & $1.4 \pm 0.6$ & $1.3 \pm 0.7$ & 0.945 \\
RBP $\left(\mathrm{g} / \mathrm{mol}\right.$.Cr) $\left.\times 10^{-2}\right)$ & $1.6 \pm 0.2$ & $1.7 \pm 0.3$ & 0.887 \\
Child-Pugh score & $5.25 \pm 0.49$ & $5.29 \pm 0.53$ & 0.414 \\
\hline
\end{tabular}

Alb: albumin; ALT: alanine aminotransferase; TBil: total bilirubin; $\mathrm{Cr}$ : creatinine;

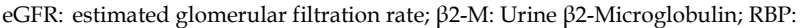
Retinol Binding protein; $\mathrm{P}$ values of independent $\mathrm{t}$ test.

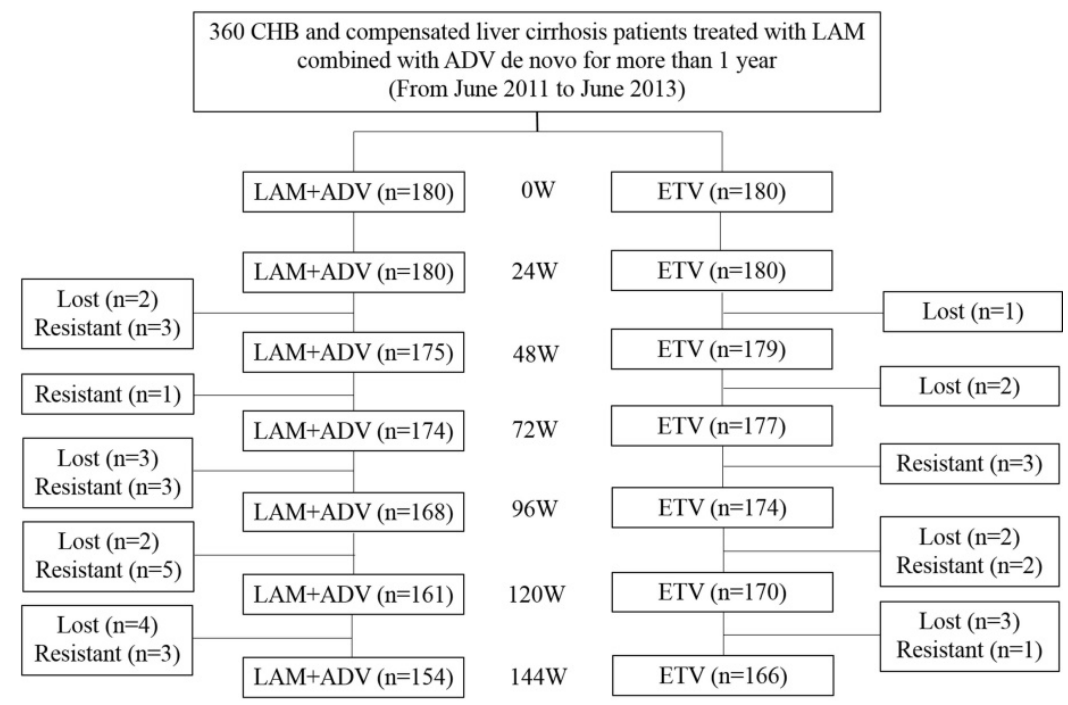

Figure 1. Flow chart of the status of $\mathrm{CHB}$ and compensated liver cirrhosis patients treated with LAM with ADV combination therapy de novo for more than 1 year followed by continued treatment with LAM and ADV combination therapy or ETV monotherapy for 144 wk. LAM: Lamivudine; ADV: Adefovir dipivoxil; and ETV: Entecavir. 


\section{Frequency of urine $\beta 2-M$ and $R B P$ abnormalities}

The cumulative occurrence of urine microprotein abnormalities is shown in Figure 2. In the control group, urine $\beta 2-\mathrm{M}$ abnormalities developed in $2.25 \%$ $(4 / 178), 4.57 \%(8 / 175)$ and $7.69 \%(13 / 169)$ of patients, and urine RBP abnormalities developed in $1.69 \%$ (3/178), $4.00 \%(7 / 175)$ and $8.28 \%(14 / 169)$ of patients in the first, second, and third year of treatment, respectively. In the experimental group, only $0.58 \%$ $(1 / 172)$ of patients developed a urine $\beta 2-\mathrm{M}$ abnormality, and only $1.16 \%(2 / 172)$ of patients developed urine RBP abnormalities in the first, second and third year, respectively. Compared with the experimental group, the occurrence of urine $\beta 2-\mathrm{M}$ abnormalities in the control group was significantly higher $(\mathrm{P}<0.001)$.

\section{Serum creatinine and glomerular filtration rate}

The trends of the serum creatinine and glomerular filtration rate in the control group and experimental group are shown in Figure 3. The mean $\pm \mathrm{SD}$ values of serum creatinine were $56.25 \pm 7.52$ $\mu \mathrm{mol} / \mathrm{L}, 60.36 \pm 8.11 \mu \mathrm{mol} / \mathrm{L}$ and $67.21 \pm 10.13 \mu \mathrm{mol} / \mathrm{L}$ in the control group at the end of the first, second, and third year, respectively. There was also an increasing trend in the serum creatinine in the experimental group. Mean $\pm \mathrm{SD}$ values were $55.16 \pm 6.21 \mu \mathrm{mol} / \mathrm{L}$, $56.56 \pm 7.03 \mu \mathrm{mol} / \mathrm{L}$ and $57.11 \pm 8.19 \mu \mathrm{mol} / \mathrm{L}$ for years 1 , 2 and 3, respectively. We also examined the eGFR in both groups. The mean \pm SD eGFR values were $91.73 \pm 7.63,87.41 \pm 11.62$ and $82.38 \pm 12.15$ in the control group in the first, second, and third year, respectively. In contrast, there was a decreasing trend in eGFR in the experimental group; the mean \pm SD eGFR values were $93.81 \pm 5.92,92.11 \pm 6.19$ and $91.77 \pm 6.28$ at the end of first, second, and third year, respectively. Baseline levels were maintained throughout the treatment course.

Further analysis demonstrated that for the control group, $4.49 \%(8 / 178), 9.14 \%(16 / 175)$ and $14.79 \%(25 / 169)$ of patients had an eGFR decline of

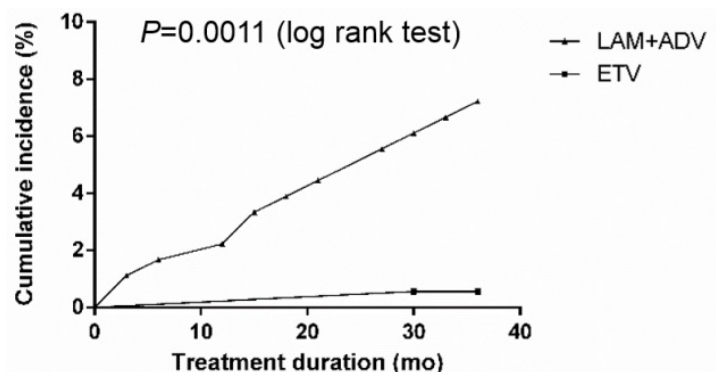

more than $30 \%$ compared to the baseline in years 1, 2, and 3, respectively. By contrast, the experimental group did not have any patients with an eGFR decline of more than $30 \%$ compared to the baseline in the first year. Only $0.56 \%(1 / 177)$ of patients in the second year, and $1.74 \%(3 / 172)$ of patients in the third year had such a decrease in eGFR. We also observed dynamic changes in the serum creatinine in the two groups during the 3 years of treatment. By the third year, $1.12 \%(2 / 178), 4.00 \%(7 / 175)$, and $5.32 \%(9 / 168)$ of patients had a creatinine increase of more than 50 $\mu \mathrm{mol} / \mathrm{L}$ from baseline in the control group, but only $1.74 \%(3 / 172)$ of patients had an increase in creatinine more than $50 \mu \mathrm{mol} / \mathrm{L}$ from baseline in the experimental group. More details are shown in Table 3. Using eGFR $<50 \mathrm{ml} / \mathrm{min} / 1.73 \mathrm{~m} 2$ as the definition of renal function impairment, $0.56 \%(1 / 178), 2.29 \%$ $(4 / 175)$ and $4.73 \%(8 / 169)$ of patients had renal function impairment in the control group in the first, second, and third year, respectively, but only $0.58 \%$ $(1 / 172)$ of patients had renal function impairment in the experimental group at the end of the third year.

Table 2. The cumulative rate of HBV DNA lower than $201 \mathrm{I} / \mathrm{ml}$, genetic mutation

\begin{tabular}{lllll}
\hline Variables & $\begin{array}{l}\text { Follow-up } \\
\text { time (Y) }\end{array}$ & LAM+ADV(\%) & ETV(\%) & $\begin{array}{l}\text { P } \\
\text { value }\end{array}$ \\
\hline $\begin{array}{l}\text { The cumulative rate } \\
\text { of HBV DNA lower }\end{array}$ & 2 & $124 / 178(69.66 \%)$ & $139 / 179(77.65 \%)$ & 0.093 \\
than 20IU/ml (\%) & 3 & $132 / 175(75.42 \%)$ & $152 / 177(85.88 \%)$ & 0.009 \\
The cumulative & 1 & $145 / 169(85.80 \%)$ & $163 / 172(94.77 \%)$ & 0.006 \\
genetic mutation & 2 & $3 / 178(1.69 \%)$ & $0 / 179(0 \%)$ & 0.123 \\
rate (\%) & 3 & $7 / 175(4.00 \%)$ & $3 / 177(1.68 \%)$ & 0.218 \\
\end{tabular}

Table 3. The changes of renal function in the patients with chronic hepatitis B and HBV-related compensated cirrhosis

\begin{tabular}{|c|c|c|c|c|}
\hline Variables & $\begin{array}{l}\text { Follow-up } \\
\text { time }(Y)\end{array}$ & LAM+ADV(\%) & ETV (\%) & P value \\
\hline \multirow{3}{*}{$\begin{array}{l}\text { Decreased in eGFR } \\
\text { more than } 30 \% \text { from } \\
\text { baseline }(\%)\end{array}$} & 1 & $8 / 178(4.49 \%)$ & $0 / 179(0 \%)$ & 0.004 \\
\hline & 2 & $16 / 175(9.14 \%)$ & $1 / 177(0.56 \%)$ & $<0.001$ \\
\hline & 3 & $25 / 169(14.79 \%)$ & $3 / 172(1.74 \%)$ & $<0.001$ \\
\hline \multirow{3}{*}{$\begin{array}{l}\text { Creatinine increased } \\
>50 \mu \mathrm{mol} / 1 \text { compared } \\
\text { with baseline }(\%)\end{array}$} & 1 & $2 / 178(1.12 \%)$ & $0 / 179(0 \%)$ & 0.248 \\
\hline & 2 & $7 / 175(4.0 \%)$ & $0 / 177(0 \%)$ & 0.007 \\
\hline & 3 & $9 / 169(5.32 \%)$ & $3 / 172(1.74 \%)$ & 0.084 \\
\hline
\end{tabular}

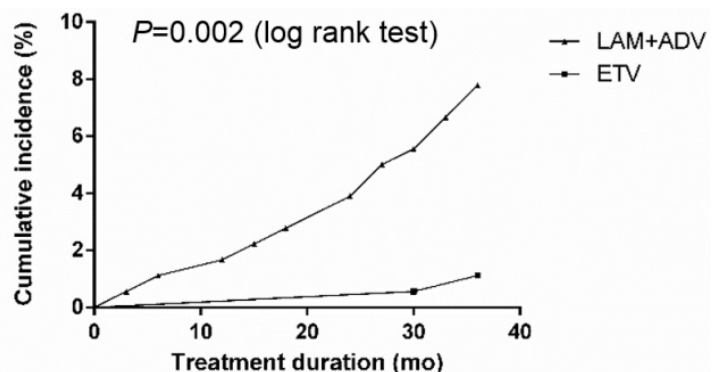

Figure 2. Cumulative incidence of urine microprotein abnormalities after continuing to receive LAM plus ADV combined treatment or switching to ETV monotherapy in chronic hepatitis B and compensated liver cirrhosis patients. Cumulative incidence of A: Urine $\beta 2$-microglobulin abnormality; and B: Retinol-binding protein abnormality. 

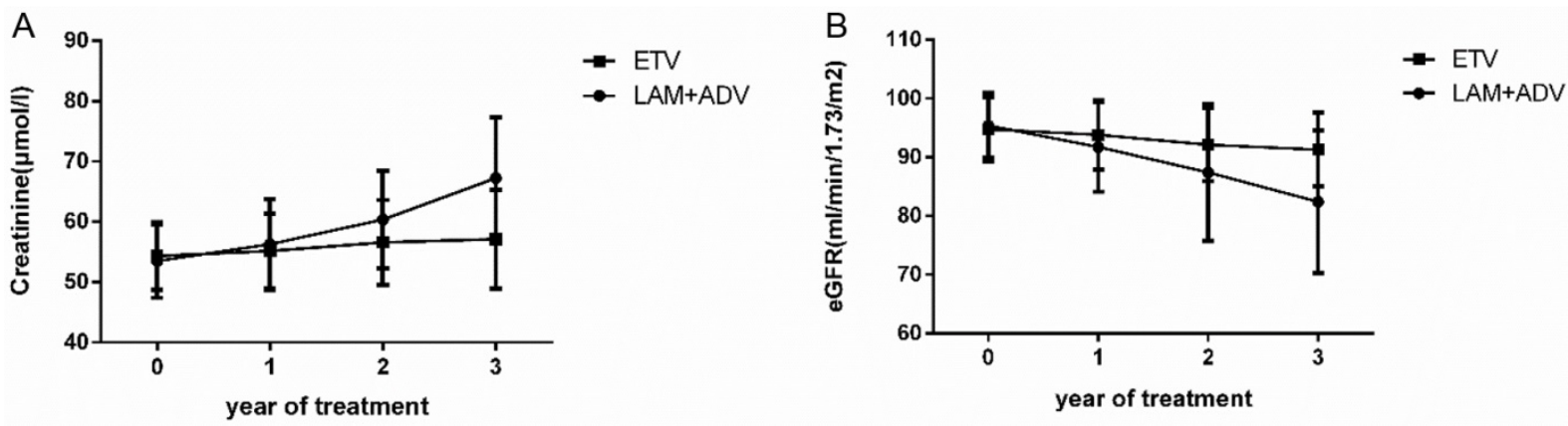

Figure 3. Dynamic change in the creatinine and estimated glomerular filtration rate (eGFR) values in the group that continued to receive LAM plus ADV combined treatment and the group that switched to ETV monotherapy.

\section{Discussion}

LAM was the first anti-HBV drug in China. Because of its convenience, definitive curative effect, and limited side effects, it has become the mainstay treatment of HBV infection. $[1,12]$ The disadvantage of LAM is its high incidence of drug resistance with long-term treatment. Based on the literature, initial LAM antiviral treatment for CHB patients has YMDD gene resistance rates of $23 \%, 46 \%, 55 \%, 65 \%$ and $71 \%$ after the first, second, third, fourth, and fifth years of use, respectively.[13] One oral prodrug of adefovir is ADV, which is an analogue of adenosine monophosphate. Intracellularly, adefovir is metabolized to adefovir diphosphate, which inhibits HBV-DNA polymerase.[14] Due to the lack of cross resistance between ADV and LAM, telbivudine (LdT) or ETV, ADV combination therapy is widely used in LAM, LdT, and ETV salvage therapy after resistance develops or initial combination therapy fails. $[15,16]$ However, in patients with $\mathrm{CHB}$ long-term treatment with ADV can potentially cause renal impairment and hypophosphatemia. In Tanaka M's study, of the 292 patients treated with ADV combined with LAM, 9.6\% patients developed kidney injury during a therapy duration of 64.3 mo.[17] Our results showed that during each of the three years of treatment for the control group, creatinine was elevated by at least 50 $\mu \mathrm{mol} / \mathrm{L}$ compared to baseline in $1.12 \%, 4.00 \%$, and $5.32 \%$ of patients, respectively. Decreases in eGFR by more than $30 \%$ of baseline occurred in $4.49 \%, 9.14 \%$, and $14.79 \%$ of patients in years 1, 2 and 3 , respectively. On the other hand, the experimental group had stable creatinine and eGFR levels.

Current evidence has indicated that in $\mathrm{CHB}$ patients, treatment with ADV increases the risk of renal dysfunction, but the mechanism remains unclear.[18, 19] It may be related to drug accumulation in the proximal tubules after long-term use of ADV. Such drug accumulation may induce reabsorption of microproteins ( $\beta 2-\mathrm{M}$ and $\mathrm{RBP})$, glucose, amino acids, calcium, and phosphorus.
Regular laboratory testing of serum or urine are important for early detection of and risk assessment for renal impairment because this condition is still reversible after prophylactic or therapeutic intervention.[20, 21] In our present study, in the 13 patients with urine $\beta 2-\mathrm{M}$ and / or RBP abnormalities, urine RBP and $\beta 2-\mathrm{M}$ increased gradually while eGFR decreased. Our results strongly suggest that if urine RBP or $\beta 2-\mathrm{M}$ abnormalities are detected in $\mathrm{CHB}$ patients, LAM plus ADV therapy should immediately be switched to ETV monotherapy.

NA-resistance pathways (rtM204I/V, rtN236T and $\mathrm{rtA} 181 \mathrm{~T} / \mathrm{V}$ ) have now been characterized. The rtM204V/I pathway is responsible for resistance to the L-nucleosides, which include LAM, LdT and ETV, while the rtN236T pathway is responsible for ADV and TDF resistance.[22, 23] Because LAM and ETV resistance is accomplished via the same pathway, some might worry that switching therapy from LAM combined with ADV to ETV monotherapy will increase resistance. Our study showed a rate of viral genetic mutations in the group that switched to ETV to be higher than the group that continued to receive LAM combined with ADV. Of the 180 patients who continued to receive LAM and ADV combination treatment, $1.69 \%(3 / 178), 4.00 \%(7 / 175)$, and $8.88 \%$ $(15 / 169)$ had genetic mutations in the first, second, and third year, respectively. On the other hand, only $0 \%(0 / 179), 1.68 \%(3 / 177)$, and $3.49 \%(6 / 172)$ of the 180 patients who received ETV monotherapy had genetic mutations consequently on the year 1,2 , and 3.

In conclusion, it is safe and effective to switch LAM and ADV combination therapy to ETV monotherapy when treating patients with $\mathrm{CHB}$ and compensated liver cirrhosis. Switching therapy for patients with $\mathrm{CHB}$ and compensated liver cirrhosis who have received LAM plus ADV therapy for more than 1 year to ETV monotherapy can improve the virological response as well as reduce ADVassociated renal impairment during long-term 
treatment. As a result, replacement should be considered as soon as possible.

\section{Acknowledgments}

This work was supported by National Key Program for infection diseases of China to YD Yang (2013ZX10002001), the Zhejiang Nature Science Foundation of China under grant No. LQ14H160011 and National Natural Science Foundation of China under Grant No.81402097.

\section{Ethics approval and consent to participate}

This study was approved by the Ethics Committee of the First Affiliated Hospital of Zhejiang University.

\section{Competing Interests}

The authors have declared that no competing interest exists.

\section{References}

1. Liaw YF, Sung JJ, Chow WC, Farrell G, Lee CZ, Yuen H, Tanwandee T, Tao QM, Shue K, Keene ON, Dixon JS, Gray DF, Sabbat J, Cirrhosis Asian Lamivudine Multicentre Study G. Lamivudine for patients with chronic hepatitis B and advanced liver disease. N Engl J Med 2004; 351: 1521-1531.

2. Lee YB, Lee JH, Choi WM, Cho YY, Yoo JJ, Lee M, Lee DH, Cho Y, Yu SJ, Kim YJ, Yoon JH, Kim CY, Lee HS. Efficacy of adefovir-based combination therapy for patients with Lamivudine- and entecavir-resistant chronic hepatitis B virus infection. Antimicrob Agents Chemother 2013; 57: 6325-6332.

3. Lian JS, Zeng LY, Chen JY, Jia HY, Zhang YM, Xiang DR, Yu L, Hu JH, Lu YF, Zheng L, Li LJ, Yang YD. De novo combined lamivudine and adefovir dipivoxil therapy vs entecavir monotherapy for hepatitis B virus-related decompensated cirrhosis. World J Gastroenterol 2013; 19: 6278-6283.

4. Gara N, Zhao X, Collins MT, Chong WH, Kleiner DE, Jake Liang T, Ghany MG, Hoofnagle JH. Renal tubular dysfunction during long-term adefovir or tenofovir therapy in chronic hepatitis B. Aliment Pharmacol Ther 2012; 35: $1317-1325$

5. Chang TT, Gish RG, de Man R, Gadano A, Sollano J, Chao YC, Lok AS, Han KH, Goodman Z, Zhu J, Cross A, DeHertogh D, Wilber R, Colonno R, Apelian D, Group BEAS. A comparison of entecavir and lamivudine for HBeAg-positive chronic hepatitis B. N Engl J Med 2006; 354: 1001-1010.

6. Terrault NA, Bzowej NH, Chang KM, Hwang JP, Jonas MM, Murad $\mathrm{MH}$ American Association for the Study of Liver D. AASLD guidelines for treatment of chronic hepatitis B. Hepatology 2016; 63: 261-283.

7. Fernandez-Fernandez B, Montoya-Ferrer A, Sanz AB, Sanchez-Nino MD, Izquierdo MC, Poveda J, Sainz-Prestel V, Ortiz-Martin N, Parra-Rodriguez A, Selgas R, Ruiz-Ortega M, Egido J, Ortiz A. Tenofovir nephrotoxicity: 2011 update. AIDS Res Treat 2011; 2011: 354908.

8. Liaw YF, Raptopoulou-Gigi M, Cheinquer H, Sarin SK, Tanwandee T, Leung N, Peng CY, Myers RP, Brown RS, Jr., Jeffers L, Tsai N, Bialkowska J, Tang S, Beebe S, Cooney E. Efficacy and safety of entecavir versus adefovir in chronic hepatitis B patients with hepatic decompensation: a randomized, open-label study. Hepatology 2011; 54: 91-100.

9. Dimou E, Papadimitropoulos V, Hadziyannis SJ. The role of entecavir in the treatment of chronic hepatitis B. Ther Clin Risk Manag 2007; 3: 1077-1086.

10. Matthews SJ. Entecavir for the treatment of chronic hepatitis B virus infection. Clin Ther 2006; 28: 184-203.

11. Chinese Society of H, Chinese Society of Infectious Diseases CMA. [The guideline of prevention and treatment for chronic hepatitis B (2010 version)]. Zhonghua Gan Zang Bing Za Zhi 2011; 19: 13-24

12. Lai CL, Chien RN, Leung NW, Chang TT, Guan R, Tai DI, Ng KY, Wu PC, Dent JC, Barber J, Stephenson SL, Gray DF. A one-year trial of lamivudine for chronic hepatitis B. Asia Hepatitis Lamivudine Study Group. N Engl J Med 1998; 339: 61-68

13. Oh JM, Kyun J, Cho SW. Long-term lamivudine therapy for chronic hepatitis B in patients with and without cirrhosis. Pharmacotherapy 2002; 22: 1226-1234.

14. Marcellin P, Chang TT, Lim SG, Tong MJ, Sievert W, Shiffman ML, Jeffers L, Goodman Z, Wulfsohn MS, Xiong S, Fry J, Brosgart CL, Adefovir Dipivoxil 437 Study G. Adefovir dipivoxil for the treatment of hepatitis B e antigen-positive chronic hepatitis B. N Engl J Med 2003; 348: 808-816.

15. Wang M, Yuan L, Qiao B, Li Y. Two rescue therapies in lamivudine-resistant patients with chronic hepatitis B in the central China: adefovir monotherapy and adefovir plus lamivudine. Virus Genes 2014; 48: 32-37.
16. Sheng YJ, Liu JY, Tong SW, Hu HD, Zhang DZ, Hu P, Ren H. Lamivudine plus adefovir combination therapy versus entecavir monotherapy for lamivudine-resistant chronic hepatitis B: a systematic review and meta-analysis. Virol J 2011; 8: 393.

17. Tanaka M, Suzuki F, Seko Y, Hara T, Kawamura Y, Sezaki H, Hosaka T, Akuta N, Kobayashi M, Suzuki Y, Saitoh S, Arase Y, Ikeda K, Kobayashi M, Kumada $\mathrm{H}$. Renal dysfunction and hypophosphatemia during long-term lamivudine plus adefovir dipivoxil therapy in patients with chronic hepatitis B. J Gastroenterol 2014; 49: 470-480.

18. Jia HY, Ding F, Chen JY, Lian JS, Zhang YM, Zeng LY, Xiang DR, Yu L, Hu JH, Yu GD, Cai H, Lu YF, Zheng L, Li LJ, Yang YD. Early kidney injury during long-term adefovir dipivoxil therapy for chronic hepatitis B. World J Gastroenterol 2015; 21: 3657-3662.

19. Yang Q, Shi YU, Yang Y, Lou G, Lv F. Association between adefovir dipivoxil treatment and the risk of renal insufficiency in patients with chronic hepatitis B: A meta-analysis. Biomed Rep 2015; 3: 269-275.

20. Cihlar T, Ho ES, Lin DC, Mulato AS. Human renal organic anion transporter 1 (hOAT1) and its role in the nephrotoxicity of antiviral nucleotide analogs. Nucleosides Nucleotides Nucleic Acids 2001; 20: 641-648.

21. Izzedine H, Launay-Vacher V, Isnard-Bagnis C, Deray G. Drug-induced Fanconi's syndrome. Am J Kidney Dis 2003; 41: 292-309.

22. Locarnini S. Primary resistance, multidrug resistance, and cross-resistance pathways in HBV as a consequence of treatment failure. Hepatol Int 2008; 2: 147-151.

23. Lei J, Wang Y, Wang LL, Zhang SJ, Chen W, Bai ZG, Xu LY. Profile of hepatitis $\mathrm{B}$ virus resistance mutations against nucleoside/nucleotide analogue treatment in Chinese patients with chronic hepatitis B. Virol J 2013; 10: 313. 